\title{
reviews
}

\section{IBP-nitrogen fixation}

\section{Christina Kennedy}

Nitrogen Fixation by Free-Living Micro-organisms. (International Biological Programme 6.) Edited by W. D. P. Stewart. Pp. xxi+471. £13.50. Symbiotic Nitrogen Fixation in Plants. (International Biological Programme 7.) Edited by P. S. Nutman. Pp.xxviii + 584. £22.00. (Cambridge University: Cambridge, London and New York, 1976.)

AN outstanding feature of the IBP synthesis meeting on nitrogen fixation held in Edinburgh in September 1973 was its international character. That very strength created a potential weakness as far as publication of the proceedings was concerned, and I remember sometimes labouring over abstracts at that meeting wondering just what it was that I had come to learn about. Messrs Stewart and Nutman, the editors, are therefore to be congratulated on the high standard of English and easy readability of both these volumes which are largely based on that IBP meeting. Both volumes contain a mixture of review articles, original research papers and a few compiled results of surveys. The reader must beware, however, of chapter titles that belie their actual contents.

The first two sections of volume 6 give roughly equal time to the two major groups of free-living nitrogen fixers, certain bacteria and blue-green algae. The reports of field research in Brazil (Dobereiner and Day, ch. 3) and in the UK (the longstanding Broadbalk experiments at Rothamsted; Day et al., ch. 5) are elegant examples of how to assess the ecological importance of bacterial nitrogen fixation, but this section would benefit from an overview of the relative importance of the various groups of free-living nitrogenfixing bacteria. There is also very little about the regulation or physiology of fixation in bacteria other than azotobacters.

If we are left wondering about the overall contribution of non-symbiotic bacteria to the world's agricultural nitrogen balance, there can be little doubt about the usefulness of bluegreen algae in certain agricultural situations. These are extensively covered in volume 6 and complemented by the excellent chapters in volume 7 on the symbiotic associa- tions of blue-green algae with plants. It is a pity that all this work is not included in the same volume in spite of the different modes of fixation.

Volume 6 continues with a section on the use of acetylene reduction as a measure of nitrogen fixation which, although useful, is not the last word, as equally valuable descriptions of this technique are described throughout research articles in both volumes. The final biochemistry section contains some well-written, if outdated, reviews and research reports on nitrogenase (this faster-moving branch of nitrogen fixation has been often reviewed recently). Still timely is $\mathrm{ch}$. 26 on reductants for nitrogenase. Hardy et al. remind us (ch. 24) that there is another world of relevant research on the chemistry of dinitrogen complexes.

Two chapters in the biochemistry section of volume 6 describe the serological identification of rhizobia and leghaemoglobin biosynthesis and therefore could usefully have been swapped for the opening three chapters on the genetics of nitrogen fixation in freeliving bacteria found in volume 7 (also a little late to be useful since most of the data has appeared elsewhere by now). We find that Rhizobium genetics is in a primitive state by comparison.

The rest of volume 7 describes nitrogen fixation in symbiotic systems, both legumes and non-legumes. It includes sections on legume inoculation (reviews and research reports), legume field experiments (mostly research reports on plant yields versus inoculation or fertilisation), and reactions of legumes to environmental stress (including legume physiology). The final section includes non-leguminous root symbioses and the

aforementioned blue-green algal-plant associations. The negative results of chapter 39 should kill the oft-sought, oft-cited nitrogen fixing role of nodules found on certain tropical leaves.

On the whole these volumes contain an unprecedented collection of information and references. Access could have been improved by better indexing, especially since some chapter titles are misleading. Since the books will probably be bought as the set, cross-indexing would have been more useful than the multi-lingual tables of contents. They are burdened with the usual disadvantages of large-scale publishing enterprises in being too expensive and too late. The meeting was in 1973 and as a consequence neither volume refers to areas of more recent importance : the role of glutamine synthetase as a regulator of nitrogen fixation, fixation by Rhizobium ex planta (or even in callus culture) or nitrogen fixation by Spirillum lipoferum in maize plants.

Finally, volume 7 closes with excerpts from the meeting's last session which was a colourful, sometimes heated, sometimes amusing discussion of possibilities for extending nitrogen fixation to other plants. Unfortunately that atmosphere dosen't come through. The written version of Ray Valentine's comments that "exploratory work... is not necessarily expensive" just doesn't make it since what he really said was "doing this stuff will only cost a few bucks."

Dr Kennedy is a senior scientific officer in the Agricultural Research Council's Unit of Nitrogen Fixation at the University of Sussex, UK.

\section{New power horizons}

G. R. Bainbridge

Energy: The Solar Hydrogen Alternative. By J. O'M Bockris. Pp. xviii+ 365. (Architectural Press: London, February 1976.) £13.50.

Practical scientists and engineers, energy planners and policy makers, to whom the author says his book is directed, will have no difficulty while reading it in coming to the conclusion that economic, large scale solar energy and hydrogen fuel systems are still many decades away. The uncertainties about continuing supplies of fossil fuels, including the problems of extracting, transporting and applying them economically will lead to increasing research and development work into several alternatives: in particular, solar and hydrogen.

The students of energy conversion, the environmentalists and people concerned in an effort to prepare for the coming era of difficulty, in which a change in energy source has possibly to be made from the diminishing fossil 